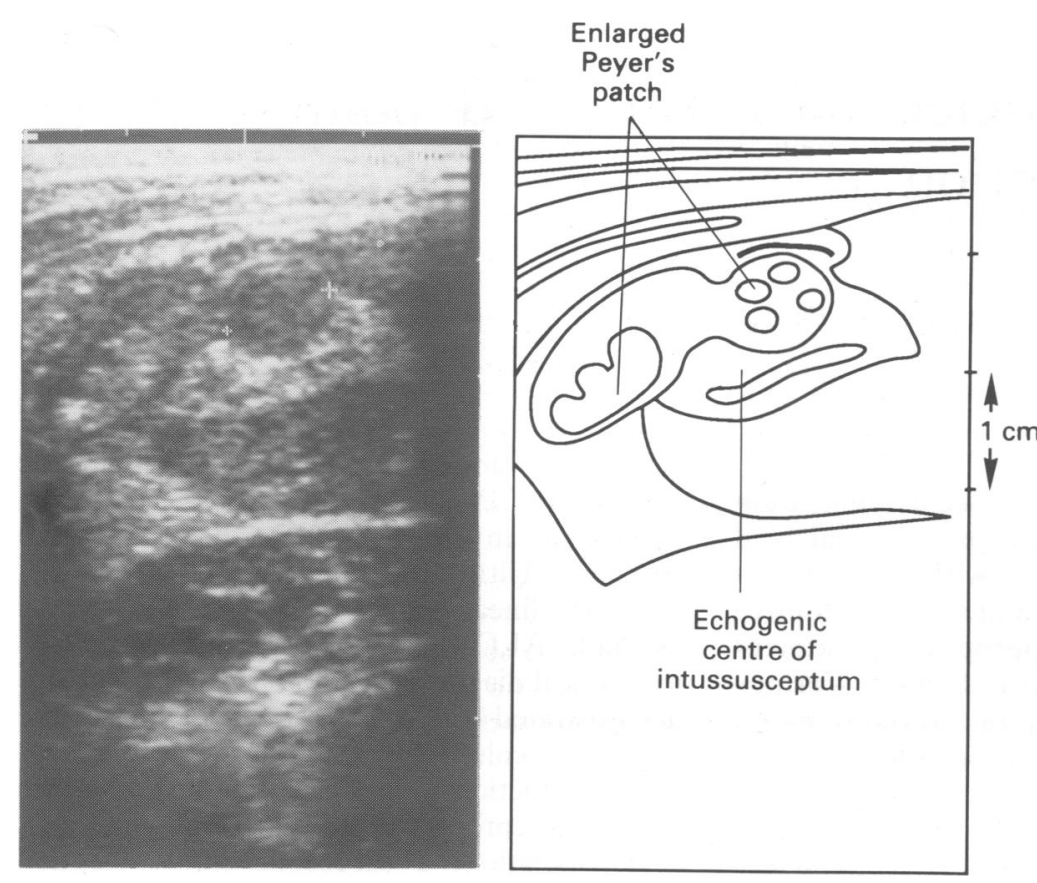

Figure 2 Typical discrete lesion (enlarged Peyer's patch) seen in transverse section at the apex of an 'idiopathic' ileocolic intussusception ( $7 \cdot 5 \mathrm{MHz}$ linear view).

or exclude intussusception in children not obviously requiring surgery, and our experience accords well with that of Pracros et al who found ultrasonography safe and reliable with neither false positives nor negatives. ${ }^{2}$ However, clearly the experience of the sonographer is important and if the diagnosis of intussusception remains uncertain after scanning with ultrasound, contrast studies should be performed.
There are several reports of children with other pathological lead points detected by ultrasound, including Meckel's diverticula ${ }^{3}$ and a small bowel lymphoma. ${ }^{4}$ One child with a false cystic lead point due to encysted fluid within the intussusception has been described but the appearances differ from our case. ${ }^{5}$ In some patients we consider that it has been possible to identify the lymphoid hyperplasia of 'idiopathic' intussusception within the intussusceptum (fig 2). Yet another diagnostic role of ultrasound is in the detection of small bowel intussusception which often proves difficult with conventional radiology. Reported examples include ileoileal intussusception occurring postoperatively ${ }^{4}$ and in Henoch-Schönlein purpura. ${ }^{6}$

In summary, not only is ultrasonography able to accurately diagnose intussusception, including the more difficult small bowel intussusception, but it may also be used to define a pathological lead point as demonstrated by this case report. This contributes to safer and simpler patient management.

1 Ong NT, Beasley SW. The leadpoint in intussusception. F Pediatr Surg 1990;25:640-3.

2 Pracros JP, Tran-Minh VA, Wright C. Ultrasound in diagnosis of intussusception. Lancet 1985;ii:733-4.

3 Itagaki A, Uchida M, Ueki K, Kajii T. Double targets sign in ultrasonic diagnosis of intussuscepted Meckel's diverticulum. Pediatr Radiol 1991;21:148-9.

4 Dinkel E, Dittrich M, Pistor G, Weitzel D, Greinacher I. Sonographic diagnosis of intussusception in childhood. $Z$ Kinderchir 1983;38:220-3.

5 Kenney IJ. Ultrasound in intussusception: a false cystic lead point. Pediatr Radiol 1990;20:349-50.

6 Martinez-Frontanilla LA, Silverman L, Meagher DP. Intussusception in Henoch-Schönlein purpura: diagnosis with ultrasound. $\mathcal{F}$ Pediatr Surg 1988;23:375-6.

\title{
Tuberculin skin reactivity four years after neonatal BCG vaccination
}

\author{
L P Ormerod, J M Garnett
}

Chest Clinic,

Blackburn Royal

Infirmary, Blackburn,

Lancashire BB2 3LR

L P Ormerod

J M Garnett

Correspondence to:

Dr Ormerod.

Accepted 29 July 1991

\begin{abstract}
Two hundred and sixty one of 279 (93.5\%) children known to be tuberculin positive shortly after receiving their neonatal BCG vaccination were still tuberculin positive at age 4 years. The results confirm the continuing effectiveness of neonatal BCG at 4 years.
\end{abstract}

Grindulis et al found a surprisingly low percentage of children to be tuberculin positive at age 22 months after neonatal BCG vaccination. ${ }^{1}$ A survey of tuberculin reactivity six to nine weeks after BCG vaccination confirmed very high effectiveness. ${ }^{2}$ A proportion of the children from that survey had their tuberculin reactivity (Arch Dis Child 1992;67:530-1) retested at age 4 years.

\section{Subjects and methods}

Altogether 863 infants whose ethnic origin was the Indian subcontinent and who were born between August 1984 and July 1985 were tuberculin tested six and nine weeks after neonatal vaccination. ${ }^{2}$ A total of $846(97 \cdot 3 \%)$ were positive grades 1 or 2 . A random one third of tuberculin positive infants from each month (totalling 279) had their skin tuberculin test (tine test, Lederle) repeated at the age of 4 years.

\section{Results}

Of the 279 children who had grade 1 or 2 positive tuberculin tests in $1984 / 5$ tested, 18 $(6 \cdot 5 \%)$ were tuberculin negative and 261 (93.5\%) 
were tuberculin positive. Altogether 251 of the 261 tuberculin positive results were grades 1 or 2 consistent with the BCG vaccination history. Ten had increased tuberculin reactions grade 3 or 4. Further investigation showed additional factors in these cases, such as household or nonhousehold contact with tuberculosis.

All 10 of the children with grade 3 or 4 positive tests have been given chemoprophylaxis because of their contact history or after extended visits to the Indian subcontinent with strongly positive tests on return.

\section{Discussion}

This study shows a continuing high tuberculin positive rate at age 4 years in those who were shown to be tuberculin positive six to nine weeks after receiving their neonatal BCG. Crawshaw and Thompson also showed 19/22 $(85 \%)$ of children to be tuberculin positive between 42 and 60 months. ${ }^{3}$ An appreciable proportion of children from the Indian subcontinent $(80 / 103,77 \cdot 6 \%)$ were still tuberculin positive at age 12 when retested for the school programme. ${ }^{4}$ Our initial results showed a $97 \cdot 3 \%$ rate of tuberculin positivity at six to nine weeks, ${ }^{2}$ and $93.6 \%$ of the neonates tuberculin positive at six to nine weeks were still tuberculin positive at age 4 years. Packe and Innes showed both a $95 \%$ positive tuberculin test rate after vaccination at age 3 months and a $65 \%$ overall protective effect. ${ }^{5}$ Hadfield $e t$ al showed a $\mathbf{9 7} \cdot 8 \%$ positive rate after neonatal vaccination with a Dermojet injector. ${ }^{6}$ Thus three separate series found tuberculin positive rates between 95-97\% after BCG vaccination in the first few months. ${ }^{256}$ This study supports earlier small studies showing a substantial tuberculin positive rates four to 12 years after vaccination. ${ }^{34} \mathrm{~A}$ negative tuberculin test does not mean that the vaccination is ineffective, however, as the degree of protection conferred on the individual is independent of the degree of tuberculin skin sensitivity induced. ${ }^{7}$

This study in children already shown to have been tuberculin positive shortly after the initial vaccination refutes the findings of Grindulis $e t$ $a l .{ }^{1}$ The explanation for the discrepancy between the results is that we were able to show an initial tuberculin response due to effective vaccination. As a quarter of the patients of Grindulis $e t$ al had no BCG scar, the likely explanation is not a failure of the vaccine but of failure of the vaccination technique.

1 Grindulis H, Baynham MID, Scott PH, Thompson RA, Wharton BA Tuberculin response two years after BCG vaccination at birth. Arch Dis Child 1984;59:614-9.

2 Ormerod LP, Garnett JM. Tuberculin response after neonatal BCG vaccination. Arch Dis Child 1988;63:1491-2.

3 Crawshaw PAG, Thomson AH. Heaf test results after Crawshaw PAG, Thomson AH. Heaf test resul
neonatal BCG. Arch Dis Child 1988;63:1490-1.

4 Teale C, Cundall DB, Pearson SB. Heaf status after infant BCG immunisation. Thorax 1989;44:843P.

5 Packe GE, Innes JA. Protective effect of BCG vaccination in infant Asians: a case-control study. Arch Dis Child 1988;63: 277-81.

6 Hadfield JW, Allan J, Windebank WJ. Sensitivity of neonates to tuberculin after BCG vaccination. $B M \mathcal{F} 1986$; 296:990-1.

7 Hart PD, Sutherland I, Thomas J. The immunity conferred by effective BCG and Vole bacillus vaccines in relation to individual variations in induced tuberculin sensitivity and to technical variations in the vaccines. Tubercle 1967;48: 201-10.

\section{Association of high fever and short bacterial excretion after salmonellosis}

Infectious Diseases
Teaching Unit,
University of Helsinki,
Finland
A Sahib El-Radhi
Epidemiological
Department,
Aurora Hospital,
Helsinki, Finland
Timo Rostila
Department of
Biomedical Sciences,
University of Tampere,
Finland
Timo Vesikari
Correspondence to:
Dr Timo Vesikari,
Department of Biomedical
Sciences, University of
Tampere, PO Box 607,
SF-33101 Tampere, Finland.
Accepted 17 December 1991
(Arch Dis Child 1992;67:531-2)

\begin{abstract}
One hundred and two children with salmonella gastroenteritis were studied for factors affecting the length of convalescent bacterial excretion. There was a significant correlation between degree of fever and duration of excretion: a fever of $\geqslant 40^{\circ} \mathrm{C}$ had the shortest and no fever the longest duration of excretion. Fever therefore appears to have a favourable prognostic influence on the length of salmonella excretion.
\end{abstract}

Excretion of salmonella is an important public health problem that requires considerable attention and resources in countries with good hygienic standards. ${ }^{1}$ Factors associated with prolonged excretion of salmonella include malnutrition, use of antibiotics, young age, symptomatic infection, and infection with salmonella other than Salmonella typhimurium. ${ }^{23}$

Accumulating evidence suggests that fever is beneficial to the infected host. ${ }^{4} \mathrm{~A}$ recent study of 125 children with salmonella gastroenteritis admitted consecutively to Ahmadi Hospital in Kuwait showed that children with a temperature greater than $40^{\circ} \mathrm{C}$ had a significantly shorter duration of bacterial excretion compared with afebrile children (AS El-Radhi, unpublished data). The aim of this study was to determine whether the same observation holds for Finnish children with salmonella gastroenteritis.

\section{Patients and methods}

The case records of all children who were hospitalised at the paediatric department of Aurora Hospital, Helsinki, Finland, with acute 